Table 1. World Hand Hygiene Day on May 5, 2022: WHO SAVE LIVES: Clean Your Hands Campaign Calls to Action

\begin{tabular}{ll}
\hline Campaign Participants & Call to Action \\
\hline Healthcare workers & "Thank you for leading by example and encouraging others to clean their hands." \\
\hline IPC practitioners & "Thank you for engaging health workers to be part of new hand hygiene initiatives." \\
\hline Quality and safety leads & "Thank you for working with infection prevention colleagues to support hand hygiene improvement." \\
\hline Facility managers & "Thank you for promoting a quality and safety culture to ensure clean hands." \\
\hline Policy makers & "Thank you for prioritizing resources, training and programmes on hand hygiene." \\
\hline People who use health care & "Thank you for getting involved in local hand hygiene campaigns and activities." \\
\hline
\end{tabular}

Note. IPC, infection prevention and control.

Further information is available on the webpage WHO SAVE LIVES: Clean Your Hands campaign and World Hand Hygiene Day 2022 (https://www.who.int/campaigns/world-hand-hygiene-day/ 2022), including an advocacy tool kit offering guidance on the campaign's objectives, key messages, and how to get involved.

Financial support. This article was supported by the World Health Organization (WHO) and the Infection Control Program (SPCI) of the University of Geneva Hospitals and Faculty of Medicine, Geneva, Switzerland. Hand hygiene research activities at the SPCI are also supported by the Swiss National Science Foundation (grant no. 32003B_163262).

Conflicts of interest. All authors report no conflicts of interest relevant to this article.

\section{References}

1. Lotfinejad N, Peters A, Tartari E, Fankhauser-Rodriguez C, Pires D, Pittet D. Hand hygiene in health care: 20 years of ongoing advances and perspectives. Lancet Infect Dis 2021;21:e209-e221.
2. Allegranzi B, Gayet-Ageron A, Damani N, et al. Global implementation of WHO's multimodal strategy for improvement of hand hygiene: a quasiexperimental study. Lancet Infect Dis 2013;13:843-851.

3. Hessels AJ, Larson EL. Relationship between patient safety climate and standard precaution adherence: a systematic review of the literature. J Hosp Infect 2016;92:349-362.

4. van Buijtene A, Foster D. Does a hospital culture influence adherence to infection prevention and control and rates of healthcare-associated infection? A literature review. J Infect Prev 2019;20:5-17.

5. Kraker MEA De, Tartari E, Tomczyk S, et al. Implementation of hand hygiene in healthcare facilities: results from the WHO Hand Hygiene Self-Assessment Framework global survey 2019. Lancet Infect Dis 2022;3099:1-10.

\title{
Multidrug-resistant organism (MDRO) contamination of privacy curtains in nursing homes
}

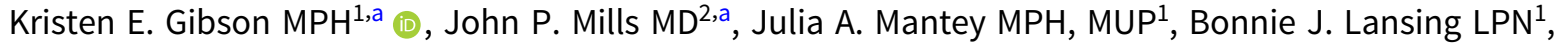 \\ Marco Cassone MD, $\mathrm{PhD}^{1}$ and Lona Mody MD, MSc ${ }^{1,3}$ \\ ${ }^{1}$ Division of Geriatric and Palliative Care Medicine, Department of Internal Medicine, University of Michigan, Ann Arbor, Michigan, ${ }^{2}$ Division of Infectious Diseases, \\ Department of Internal Medicine, University of Michigan, Ann Arbor, Michigan and ${ }^{3}$ Geriatrics Research Education and Clinical Center, Veterans' Affairs Ann Arbor \\ Healthcare System, Ann Arbor, Michigan
}

To the Editor - Privacy curtains are an understudied potential vector for pathogen transmission. ${ }^{1,2}$ They are ubiquitous in healthcare facilities and are touched frequently by healthcare workers (HCWs), often between hand hygiene and patient interactions. ${ }^{3-6}$ Also, they are infrequently changed or cleaned. Best practices in terms of the optimal materials and usage have not been well established. In this study, we evaluated the microbial concordance and

Author for correspondence: Lona Mody, E-mail: lonamody@umich.edu

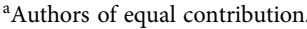

PREVIOUS PRESENTATION. This research was presented at the 2019 European Congress of Clinical Microbiology and Infectious Diseases on April 16, 2019, in Amsterdam, Netherlands, and at the 2019 American Geriatrics Society annual meeting on May 2, 2019, in Portland, Oregon.

Cite this article: Gibson KE, et al. (2022). Multidrug-resistant organism (MDRO) contamination of privacy curtains in nursing homes. Infection Control \& Hospital Epidemiology, 43: 666-668, https://doi.org/10.1017/ice.2021.60 strain similarity between multidrug-resistant organism (MDRO) contamination of curtains and patient colonization.

\section{Methods}

A prospective cohort study was conducted in 6 nursing homes in southeast Michigan between November 2013 and May 2016. ${ }^{7}$ After obtaining informed consent, we obtained cultures from several patient body sites and high-touch surfaces in the patient rooms, including the privacy curtain, at admission, day 14 , day 30 and monthly thereafter up to 6 months. ${ }^{8}$ Age, sex, race, and risk factors for MDRO colonization (functional disability, ${ }^{9}$ indwelling devices, comorbidities, prior antibiotic use, hospitalization length), and data on facility curtain changing policies were collected. The University of Michigan institutional review board approved the study. 
Table 1. Characteristics of Nursing Home Patients on Enrollment

\begin{tabular}{|c|c|c|c|c|}
\hline Characteristic & All Patients $\mathrm{N}=625$ & $\begin{array}{l}\text { Curtain Contamination at Any } \\
\text { Time, Any MDRO N=250 }\end{array}$ & $\begin{array}{l}\text { No Curtain Contamination at Any } \\
\text { Time, Any MDRO N=375 }\end{array}$ & $P$ Value \\
\hline Age, mean (SD) & $74.7(12.2)$ & $74.7(12.1)$ & $75.8(12.2)$ & $.993^{\mathrm{a}}$ \\
\hline Male sex, no. (\%) & $262 / 625(41.9)$ & $108 / 250(43.2)$ & $154 / 375(41.1)$ & $.596^{\mathrm{b}}$ \\
\hline Non-Hispanic white, no. (\%) & $384 / 625(61.4)$ & $143 / 250(57.2)$ & $241 / 375(64.3)$ & $.075^{\mathrm{b}}$ \\
\hline Device use, No. (\%) & $65 / 625(10.4)$ & $34 / 250(13.6)$ & $31 / 375(8.3)$ & $.032^{\mathrm{b}}$ \\
\hline Antibiotic use in past $30 \mathrm{~d}$, no. (\%) & $371 / 610(60.8)$ & $157 / 246(63.8)$ & $214 / 364(58.8)$ & $.212^{\mathrm{b}}$ \\
\hline History of MRSA, no. (\%) & $23 / 616(3.7)$ & $12 / 244(4.9)$ & $11 / 372(3.0)$ & $.209^{b}$ \\
\hline History of VRE, no. (\%) & $12 / 613(2.0)$ & $11 / 241(4.6)$ & $1 / 372(0.3)$ & $.000^{c}$ \\
\hline History of R-GNB, no. (\%) & $34 / 601(5.7)$ & $21 / 237(8.9)$ & $13 / 364(3.6)$ & $.006^{\mathrm{b}}$ \\
\hline Charlson comorbidity score, mean (SD) & $2.5(2.1)$ & $2.7(2.0)$ & $2.4(2.1)$ & $.051^{\mathrm{a}}$ \\
\hline Charlson score $>2$ & $278 / 625(44.5)$ & $128 / 250(51.2)$ & $150 / 375(40.0)$ & $.006^{\mathrm{b}}$ \\
\hline PSMS score & $14.5(4.7)$ & $15.0(4.8)$ & $14.2(4.6)$ & $.022^{a}$ \\
\hline Open wounds & $273 / 624(43.8)$ & $110 / 250(44.0)$ & $163 / 374(43.6)$ & $.918^{\mathrm{b}}$ \\
\hline $\begin{array}{l}\text { Length of preadmission hospitalization, } \\
\text { mean (SD) }\end{array}$ & $\begin{array}{c}7.1(6.7) \\
(\mathrm{N}=621 ; \\
\text { range } 0-75)\end{array}$ & $\begin{array}{c}8.0(8.1) \\
(\mathrm{N}=248 ; \\
\text { range } 0-75)\end{array}$ & $\begin{array}{c}6.5(5.2) \\
(\mathrm{N}=373 ; \\
\text { range } 0-44)\end{array}$ & $.005^{a}$ \\
\hline \multicolumn{5}{|c|}{ Functional disabilities on enrollment, No. (\%) } \\
\hline Ambulation & $400 / 625(64.0)$ & $175 / 250(70.0)$ & $225 / 375(60.0)$ & $.011^{\mathrm{b}}$ \\
\hline Dressing & $379 / 625(60.6)$ & $162 / 250(64.8)$ & $217 / 375(57.9)$ & $.082^{\mathrm{b}}$ \\
\hline Bathing & $332 / 625(53.1)$ & $144 / 250(57.6)$ & $188 / 375(50.1)$ & $.067^{\mathrm{b}}$ \\
\hline Toileting & $210 / 625$ (33.6) & $97 / 250(38.8)$ & $113 / 375(30.1)$ & $.025^{\mathrm{b}}$ \\
\hline Grooming & $177 / 625(28.3)$ & $78 / 250(31.2)$ & $99 / 375(26.4)$ & $.192^{\mathrm{b}}$ \\
\hline Feeding & $43 / 625(6.9)$ & $19 / 250(7.6)$ & $24 / 375(6.4)$ & $.561^{b}$ \\
\hline
\end{tabular}

Note. MDRO, multidrug-resistant organism; SD, standard deviation; PSMS, Physical Self-Maintenance Scale.

${ }^{\text {a C}}$ Calculated using a 2-sided $t$ test.

${ }^{b}$ Calculated using the Pearson $\chi^{2}$ test.

${ }^{c}$ Calculated using the Fisher exact test.

At each visit, swabs (Bacti-swabs, Remel, Lenexa, Kansas) were used to sample patient body sites (dominant hand, nares, oropharynx, groin, perianal area, wounds if present, enteral feeding tube insertion site, suprapubic catheter site) and high-touch surfaces (bed controls, bedside table, nurse call button, privacy curtain, toilet seat, door knob, television remote control, bed rail, wheelchair handles) in the patient's room as previously described. ${ }^{8}$ For privacy curtains, an area of $\sim 43 \mathrm{~cm}^{2}$ was swabbed from the leading edge of the flame-retardant polyester curtain.

Swabs were cultured for methicillin-resistant Staphylococcus aureus (MRSA), vancomycin-resistant Enterococcus (VRE), and resistant gram-negative bacilli (R-GNB). ${ }^{7}$ Pulsed-field gel electrophoresis (PFGE) was performed on a subset of MRSA and VRE isolates as previously described. ${ }^{8}$ Isolates were placed in the same pulsotype if their SmaI restriction patterns were $\geq 80 \%$ similar.

Baseline characteristics were compared between patients with an MDRO-contaminated curtain at any point in the study and those with no contamination. The Student $t$ test was used to compare continuous variables; the Pearson $\chi^{2}$ test and the Fisher's exact test were used for categorical variables. The relationship between curtain MDRO contamination and patient MDRO colonization were calculated using $\chi^{2}$ tests.

\section{Results}

Of the 625 study patients, $250(40.0 \%)$ had an MDRO-contaminated privacy curtain at some point during the study. Those patients were more likely to have an indwelling device in place, multiple comorbidities, a higher PSMS score, a longer hospital stay prior to nursing home admission, and disabilities related to ambulation and toileting (Table 1).

Of 1,521 total curtain samples, $334(22.0 \%)$ were contaminated with an MDRO, including 210 (13.8\%) with VRE, 94 (6.2\%) with R-GNB, and 74 (4.9\%) with MRSA (Supplementary Table 1 online). The most commonly isolated R-GNB were Pantoea spp (47 isolates), Acinetobacter baumannii (21 isolates), and Enterobacter cloacae (10 isolates). MDRO prevalence varied among facilities, ranging from $11.9 \%$ to $28.5 \%$ (VRE, $7.1 \%-17.6 \%$; R-GNB, 2.0\%- 11.6\%; MRSA, $2.8 \%-8.8 \%)$. There were 36 cases ( $8.8 \%$ of at-risk patients) of new MRSA curtain contamination and 56 cases ( $15.8 \%$ of at-risk patients) of new VRE contamination. In 47 (51.0\%) instances, MRSA or VRE patient colonization preceded the positive curtain sample. Among instances in which isolates from the curtain as well as the patient and/or the environment were available, identical PFGE patterns were identified in 15 of 19 visits (78.9\%) for MRSA and 14 of 25 visits (56.0\%) for VRE (Supplementary Table 2 online).

\section{Discussion}

We found high rates of MDRO contamination among privacy curtains in occupied rooms at 6 nursing facilities. Of 625 patients, 250 (40\%) had an MDRO isolated from his or her privacy curtain at some point (334 of 1,521 samples, $22 \%$ of sampling visits), and VRE was the most common (13.8\% of samples). New MDRO 
curtain contamination occurred predominantly in rooms with preexisting patient colonization, often with matching isolates.

Privacy curtains serve an important role in healthcare settings, but they are a potential pathogen reservoir due to large surface area and frequent contact by HCWs and patients. ${ }^{1-4,6}$ Prior studies in intensive care units have reported rapid MRSA or VRE contamination, within 1 week of new curtain placement. ${ }^{4,5}$ Transmission of bacteria to HCW hands occurs after $50 \%$ of curtain contacts. ${ }^{10}$ Our study showed the more common sequence of events to be patient colonization followed by curtain contamination; however, in some cases in which curtain contamination preceded the patient colonization, the curtain was a plausible source of transmission to patients.

In this hypothesis-generating study, we did not assess the directionality of MDRO contamination or quantify the level of curtain contamination. Curtain cleaning practices, optimal frequency of cleaning, and any potential transmission to roommates should be investigated in-depth. To our knowledge, this is the first investigation of curtain contamination in nursing home settings, in which the prevalence of MDRO patient colonization is particularly high. Widespread curtain contamination has been linked to lack of regular disinfection or replacement. ${ }^{6}$ Antimicrobial curtains, including antimicrobial textile technology, have been studied as a potential solution. ${ }^{5}$

Action can and should be taken to decrease curtain contamination, including standard practice guidelines for cleaning or replacing curtains, and implementation of simple strategies, such as better handwashing by medical staff, patients, and visitors, while also considering alternative designs, such as removable handles, retractable partitions, and argon glass doors.

Acknowledgments. We thank all nursing home patients and HCWs who participated in this research study.

Financial support. This work was supported by the National Institutes of Health (grant nos. RO1 AG041780 and K24 AG050685).
Conflicts of interest. All authors report no conflicts of interest relevant to this article.

Supplementary material. To view supplementary material for this article, please visit https://doi.org/10.1017/ice.2021.60

\section{References}

1. Fijan S, Turk SS. Hospital textiles, are they a possible vehicle for healthcare-associated infections? Int J Environ Res Public Health 2012;9: 3330-3343.

2. Mitchell BG, Dancer SJ, Anderson M, Dehn E. Risk of organism acquisition from prior room occupants: a systematic review and meta-analysis. J Hosp Infect 2015;91:211-217.

3. Shek K, Patidar R, Kohja Z, et al. Rate of contamination of hospital privacy curtains in a burns/plastic ward: a longitudinal study. Am J Infect Control 2018;46:1019-1021.

4. Ohl M, Schweizer M, Graham M, Heilmann K, Boyken L, Diekema D. Hospital privacy curtains are frequently and rapidly contaminated with potentially pathogenic bacteria. Am J Infect Control 2012;40: 904-906.

5. Schweizer M, Graham M, Ohl M, Heilmann K, Boyken L, Diekema D. Novel hospital curtains with antimicrobial properties: a rando mized, controlled trial. Infect Control Hosp Epidemiol 2012;33: 1081-1085.

6. Sehulster LM. Healthcare laundry and textiles in the United States: review and commentary on contemporary infection prevention issues. Infect Control Hosp Epidemiol 2015;36:1073-1088.

7. Mody L, Foxman B, Bradley S, et al. Longitudinal assessment of multidrug-resistant organisms in newly admitted nursing facility patients: implications for an evolving population. Clin Infect Dis 2018;67:837-844.

8. Cassone M, Mantey J, Perri MB, et al. Environmental panels as a proxy for nursing facility patients with MRSA and VRE colonization. Clin Infect Dis 2018;67:861-868.

9. Lawton MP, Brody EM. Assessment of older people: self-maintaining and instrumental activities of daily living. Gerontologist 1969;9:179-186.

10. Larocque M, Carver S, Bertrand A, McGeer A, McLeod S, Borgundvaag B. Acquisition of bacteria on healthcare workers' hands after contact with patient privacy curtains. Am J Infect Control 2016;44:1385-1386.

\title{
Wither proper evaluation of falls for coexisting systemic infections?
}

\author{
Farrin A. Manian MD, MPH ${ }^{1}$ and Marine Lipartia $\mathrm{MD}^{2}$ \\ ${ }^{1}$ Department of Medicine, Mercy-St Louis, St Louis, Missouri and ${ }^{2}$ NUMEO Medical, Lexington, Massachusetts
}

To the Editor-We read the Society for Healthcare Epidemiology of America (SHEA) document on the reliability of nonlocalizing signs and symptoms as potential indicators of the presence of infection in nursing-home residents ${ }^{1}$ with great interest. The authors should be commended for their work aimed at curbing the overuse of antibiotics by highlighting the problem of frequent overdiagnosis of bacterial infections in long-term care facilities based on nonlocalizing signs and symptoms. We believe, however, that the section addressing falls, a common presentation in the elderly, ${ }^{2}$ deserves further discussion.

\footnotetext{
Author for correspondence: Farrin A. Manian, E-mail: Farrinman@gmail.com

Cite this article: Manian FA and Lipartia M. (2022). Wither proper evaluation of falls for coexisting systemic infections?. Infection Control \& Hospital Epidemiology, 43: 668-669, https://doi.org/10.1017/ice.2021.56
}

More specifically, the authors "do not recommend that clinicians evaluate a resident who has experienced a fall for the presence of infection." Visibly absent in the statement was a qualifier, such as in the absence of additional signs and symptoms of infection or "in isolation," terms used when also recommending against prompt evaluation for infection in other nonspecific symptoms (eg, behavioral changes exclusive of delirium, functional decline, or anorexia). The authors' argument against evaluation of falls as a potential sign of an underlying infection seems to revolve primarily around their concern over providers' overdiagnosis of urinary tract infections (UTIs) in a patient population at high risk of asymptomatic bacteriuria, which may in turn lead to unnecessary use of antibiotics for presumed urinary tract infection (UTI). They also add that their literature search failed to identify studies evaluating the association of falls with other infectious syndromes, 